\title{
A hydrothermal apparatus for X-ray absorption spectroscopy of hydrothermal fluids at DESY
}

S. Klemme ${ }^{1 *}$, M. Feldhaus ${ }^{1}$, V. Potapkin ${ }^{1}$, M. Wilke ${ }^{2}$, M. Borchert ${ }^{1,4}$, M. Louvel ${ }^{1}$, A. Loges ${ }^{3}$, A. Rohrbach ${ }^{1}$, P. Weitkamp ${ }^{1}$, E. Welter ${ }^{4}$, M. Kokh ${ }^{2}$, C. Schmidt ${ }^{5}$, D. Testemale ${ }^{6}$

1 Institut für Mineralogie, Universität Münster, Corrensstrasse 24, 48149 Münster, Germany 2 Institut für Geowissenschaften,Universität Potsdam, Karl-Liebknecht-Str. 24-25, 14476 Potsdam, Germany 3 Institut für geologische Wissenschaften, Freie Universität Berlin, Malteserstr. 74-100, 12249 Berlin, Germany 4 Deutsches Elektronen-Synchrotron DESY - A Research Centre of the Helmholtz Association, Notkestrasse 85, 22607 Hamburg, Germany 5 GFZ German Research Centre for Geosciences, Telegrafenberg, 14473 Potsdam, Germany 6 Univ. Grenoble Alpes, CNRS, Grenoble INP, Institut Néel, 38000 Grenoble, France

${ }^{*}$ corresponding author

Keywords: high pressure, autoclave, synchrotron, DESY, XAS, X-ray absorption spectroscopy, hydrothermal, ore deposit, hydrothermal fluid, $\mathrm{H}_{2} \mathrm{O}$, Raman Spectroscopy, Centre for Molecular Water Science

\section{Abstract}

We present a new autoclave, which enables in-situ characterization of hydrothermal fluids at high pressures and high temperatures at synchrotron X-ray radiation sources. The autoclave has been specifically designed to enable X-ray absorption spectroscopy in fluids with applications to mineral solubility and element speciation analysis in hydrothermal fluids in complex compositions. However, other applications such as Raman spectroscopy in high-pressure fluids are also possible with the autoclave. Preliminary results on scheelite dissolution in fluids of different compositions show that the autoclave is well suited to study the behavior of ore-forming metals at $\mathrm{P}-\mathrm{T}$ conditions relevant to the Earth's crust.

\section{Introduction}

Most ore deposits in the Earth's crust formed via precipitation of metal-rich minerals from hydrothermal fluids. Fluid inclusions in minerals may provide mainly qualitative information about the chemical composition of these fluids $\left(\right.$ e.g., $\left.{ }^{1-3}\right)$, but fluid inclusion studies do not provide much information about the speciation or complexation of metals or other elements in these hydrous fluids, especially as fluids display often (but not always) large changes upon cooling ${ }^{4-6}$. Hence, non-quenchable properties such as the speciation of elements in hydrothermal fluids are best 
studied experimentally in-situ at high-pressures and high temperatures.

Previously, hydrothermal diamond anvil cells (HDAC) have been used to study fluids at high pressures and high temperatures ${ }^{7-13}$. However, the application of diamond anvil cells has several limitations: The diamonds are relatively thick which causes significant attenuation of X-rays ${ }^{14,15}$, the sample volume is very small, usually about $0.005-0.1 \mathrm{~mm}^{3}$, and the cell design does not permit experiments along an isobar. Furthermore, the pressure in HDAC experiments cannot be accurately determined and precisely controlled ${ }^{11,16}$. Therefore, experiments at synchrotron radiation sources with HDAC equipment must be done by specialists, and this has limited the accessibility and the productivity of such equipment. Other designs of hydrothermal cells permit only the study of dilute, simple, and non-aggressive fluids that do not attack the walls of the autoclave and the high-pressure (HP) windows (e.g., ${ }^{17}$ ). A more recently developed hydrothermal autoclave design has enabled routine spectroscopic studies of fluids at high pressures and temperatures, including aggressive $\mathrm{Cl}$-, F- or S-rich fluids ${ }^{18}$.

Here we present a new version of this autoclave, which was tested at DESY in Hamburg. It has been installed at the applied X-ray absorption beamline P65 ${ }^{19}$ and can also be used at the advanced X-ray absorption beamline P6 ${ }^{19}$. The main aim was to design an autoclave system that is safe and easy to use, and enables experimentation with highly reactive high-temperature high-pressure fluids. This equipment will be an essential part of the new "Centre for Molecular Water Science" initiative at DESY, which focuses on the physics and chemistry of aqueous fluids. This new autoclave at DESY will complement the existing experimental high-pressure equipment at DESY (e.g., ${ }^{20,21}$ ), which now encompasses the entire pressure-temperature regimes relevant to the Earth's crust, the mantle, and core.

\section{The hydrothermal apparatus at DESY}

\section{Autoclave}

The design of the pressure vessel follows Testemale's original design ${ }^{18}$, but some significant adjustments were made to improve the ease of experimentation with the apparatus. The autoclave is designed so that it may be used both for X-ray and infrared-Raman spectroscopy.

The body of the autoclave is made from high-performance steels, which is surrounded by a cooling jacket. The autoclave is closed by a high tensile steel nut, which contains feedthroughs for thermocouple wires and electrical supply wires for the heater. The autoclave is pressurized by 
He-gas, and has one gas inlet and one outlet. The gas is supplied to the autoclave using a NovaSwiss (Nova Werke, Effretikon, Switzerland) high performance membrane gas compressor. Pressure is monitored and controlled using a commercial pressure control unit (Maximator, France).

The autoclave has three windows (Fig. 1) to permit measurements in transmission but also measurements of the fluorescence signal ( $90^{\circ}$ to the incoming synchrotron $X$-ray beam). The window materials used for X-ray spectroscopy are made of vitreous carbon (Sigradur, HTW Hochtemperatur-Werkstoffe $\mathrm{GmbH}$, Germany), as initial tests with Be-windows showed that the Be itself contained significant amounts of trace elements (Fe, Cu, Ni, Y, W, Ge, REE), often at levels much higher than $50 \mu \mathrm{g} / \mathrm{g}$ each ${ }^{22}$. Windows for IR-Raman spectroscopy are made from commercially available sapphire windows (Thorlabs, USA). The chemical composition of the vitreous carbon was checked by electron microprobe and laser ablation-inductively coupled plasma mass spectrometry (LA-ICPMS) at the University of Münster, Germany. Both analyses did not give quantitative results as standard materials or internal reference elements were not available. However, a wavelength dispersive spectroscopy (WDS) scan over the entire signal band with the electron microprobe and qualitative measurements with LA-ICPMS indicate remarkable low count rates of the aforementioned trace elements which indicates concentrations below the $\mu \mathrm{g} / \mathrm{g}$ level.

The internal sample cell for X-ray spectroscopy is also made from vitreous carbon (Sigradur, HTW Hochtemperatur-Werkstoffe $\mathrm{GmbH}$, Germany), with $4 \mathrm{~mm}$ internal diameter (I.D.) and $10 \mathrm{~mm}$ outer diameter (O.D.). The sample, which in most cases will consist of a liquid together with solids, is placed within the vitreous carbon tube (see Fig 2), and it is contained within the tube by two polished vitreous carbon pistons that are sealed with viton O-rings. These pistons can move freely to account for volume changes with increasing or decreasing pressure. In order to minimize absorption of the internal sample cell, a small recess is machined in the center of vitreous carbon tube resulting in a $6 \mathrm{~mm}$ O.D. at measurement position (Fig. 2). This is an easy task given the ease and safeness of machining vitreous carbon.

The internal sample cell (i.e. the carbon tube with the sample) is heated with resistive wire heaters, made either from stainless steel or $\mathrm{W}$-wire of $0.1 \mathrm{~mm}$ thickness. The sample cell and the heater are surrounded with concentric rings of alumina-based ceramics which reduce the gas volume and thermal gradients within the autoclave. Two thermocouples are used to monitor and control temperatures during the experiments. The thermal gradient from the top of the heater to the center of the sample cell is ca. $35 \mathrm{~K}$. The sample itself, which consist mainly of hydrous fluids, is 
expected to convect along the thermal gradient so that the entire fluid is held at constant temperature. The temperature at the measurement position is determined by calibration runs with pure water for a given assembly and pressure. This calibration is based on the density by the equation of state of water ${ }^{23}$ and the measured absorption of X-rays at a given energy, using the absorption cross-section of the Elam database ${ }^{24}$. Pressures are automatically measured and controlled using a custom-built pressure regulation system, based on the design of highperformance high-pressure valves ${ }^{25}$. Temperatures are controlled using conventional Eurotherm (Schneider Electric Systems GmbH, Germany) temperature controllers.

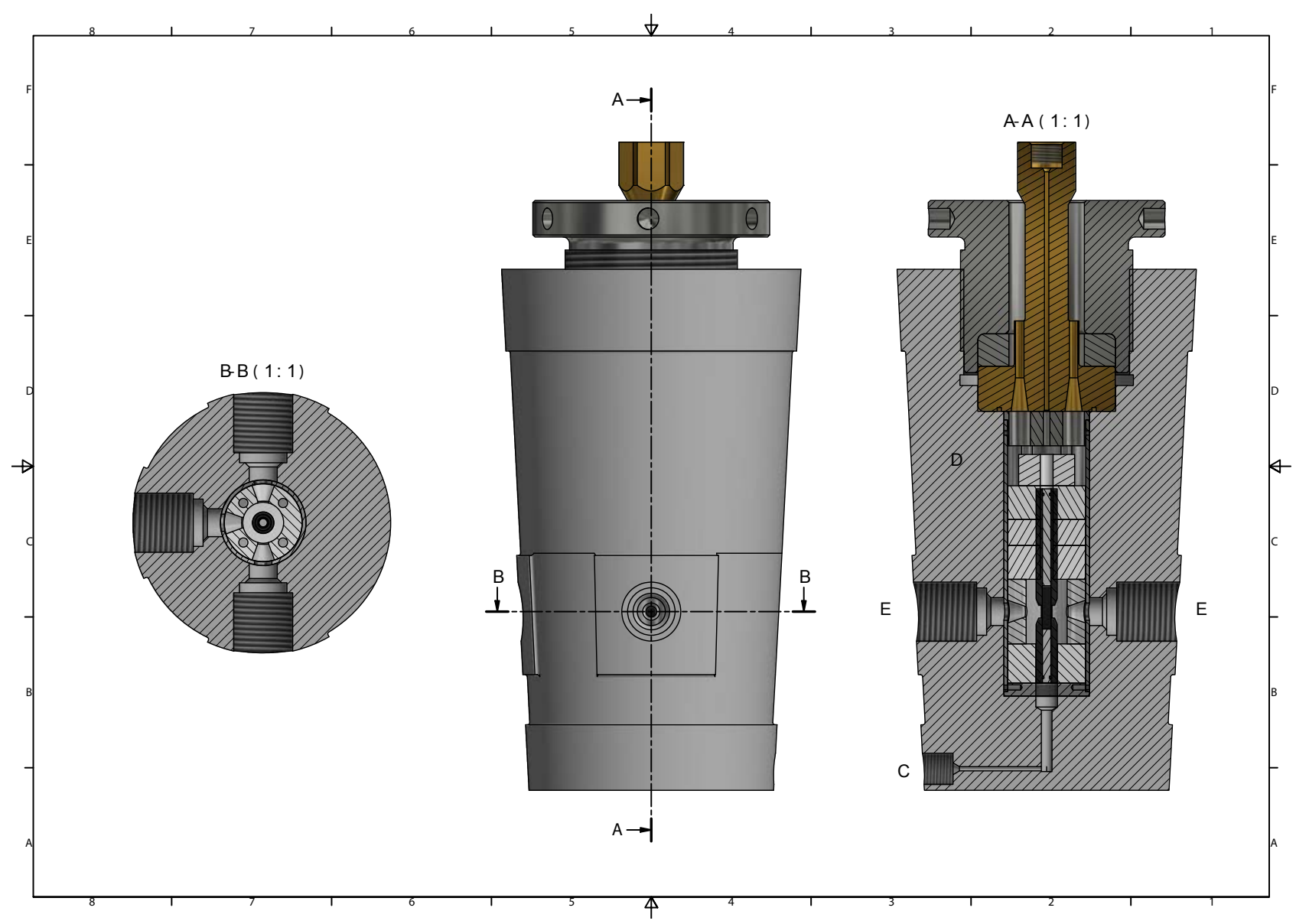

Fig. 1. Center: The autoclave (without cooling jacket) fully assembled with top nut, heater, and openings for windows. The autoclave is $46 \mathrm{~cm}$ high and $15 \mathrm{~cm}$ in diameter and has three windows in the lower third, two in the direction of the X-ray beam to allow transmission measurements, and one at $90^{\circ}$ to the incoming X-ray beam to collect the fluorescence signal. Left: B-B; horizontal section through the autoclave at the position of the three windows. Right: Vertical cross section (A-A), together with the top nut, heater, windows, and sample cell. The sample container is depicted as a black tube, together with pistons (for clarity only depicted in grey), all made from vitreous carbon. D: steel body of the autoclave. E: Window seats, C: Gas inlet (supplied from the He-gas compressor and the pressure control unit. 


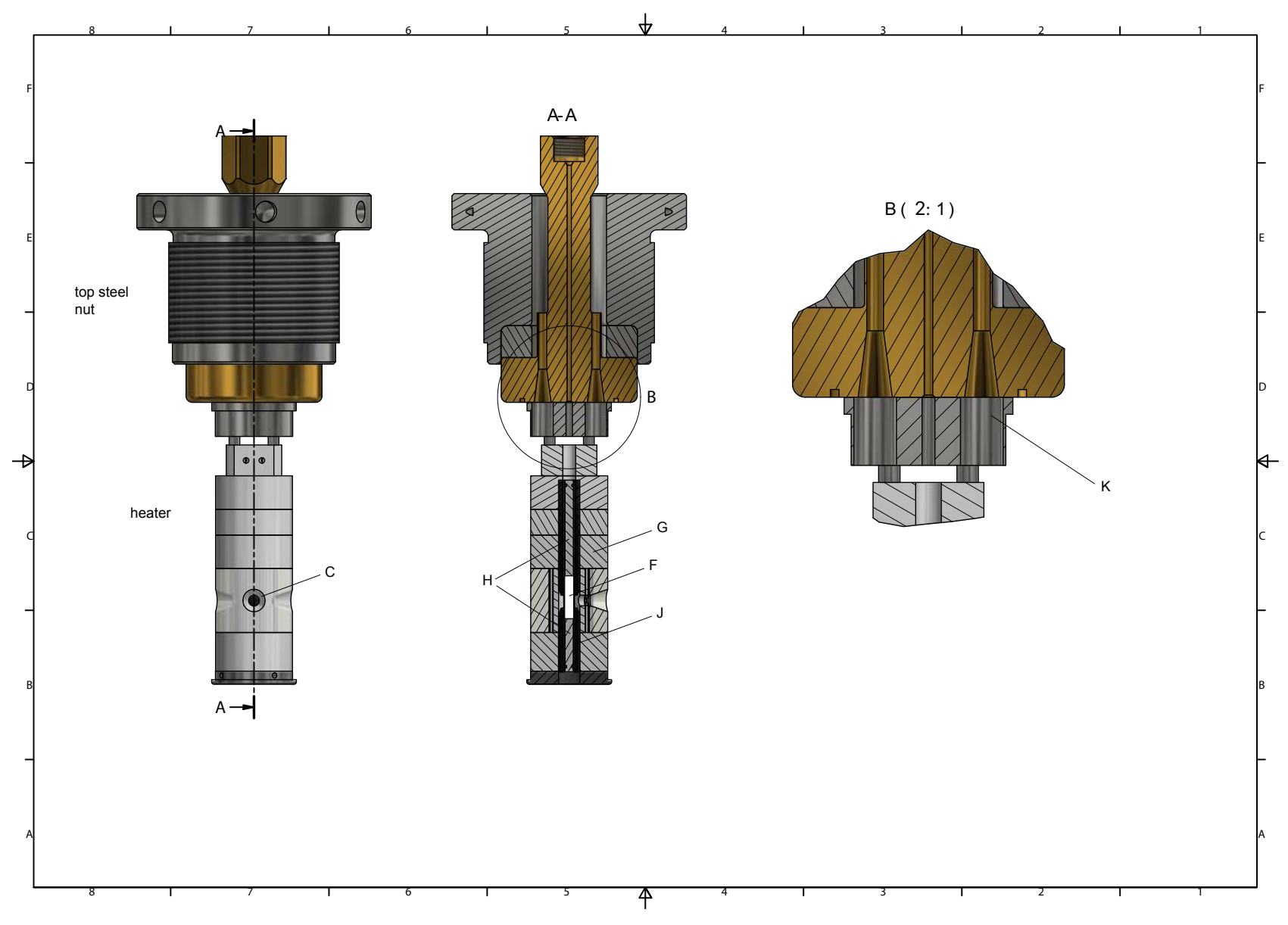

Fig. 2. Left: The fully assembled heater assembly together with the top steel nut of the autoclave. The heater assembly has three openings for windows, of which the front window $(C)$ can be seen. Center: The heater assembly consists of a resistive wire heater surrounded by several stacks of ceramic, alumina based, insulation materials (G, see text for details). A cross section through the top nut and the heater assembly (A-A) depicts inner parts of the heater assembly and the sample cell, the latter of which is made of vitreous carbon and contains the fluid sample $(F)$. The sample cell consists of a $100 \mathrm{~mm}$ long tube of vitreous carbon $(\mathrm{J})$ with $10 \mathrm{~mm}$ O.D and $4 \mathrm{~mm}$ I.D. The tube has a $5 \mathrm{~mm}$ long recess at which the tube walls are only $2 \mathrm{~mm}$ thick. The fluid sample $(\mathrm{F})$ is contained by two vitreous carbon pistons $(\mathrm{H})$ which have an outer diameter of $3.9 \mathrm{~mm}$. Note that the pistons $(\mathrm{H})$ are depicted in grey for better visualization, although they are made from the same material as the tube itself. Both pistons have small grooves at the end that hold fitting O-rings (Viton, DuPont, USA). Right: Connection between heater (with ceramic insulation) and the top nut, together with feedthroughs for heater and thermocouple wires (K). 


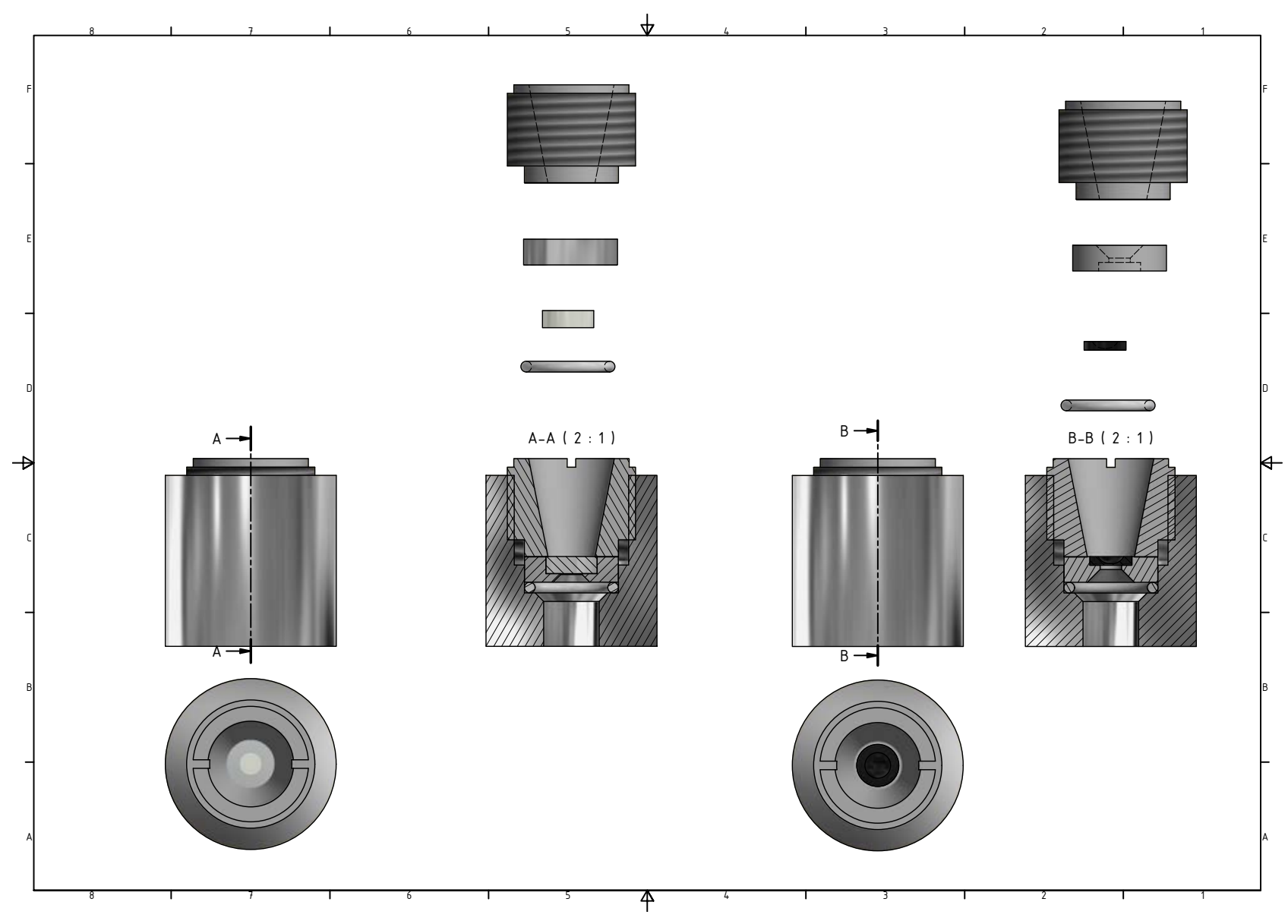

Fig 3. Window seats for vitreous carbon windows (right side) and polished sapphire single crystal windows (left side). The windows are mounted in the seats using ceramic or metal guide rings, and O-rings (Viton, DuPont, USA). The carbon windows are used for X-ray spectroscopy, whereas the sapphire windows may be used for IR-Raman spectroscopy. 


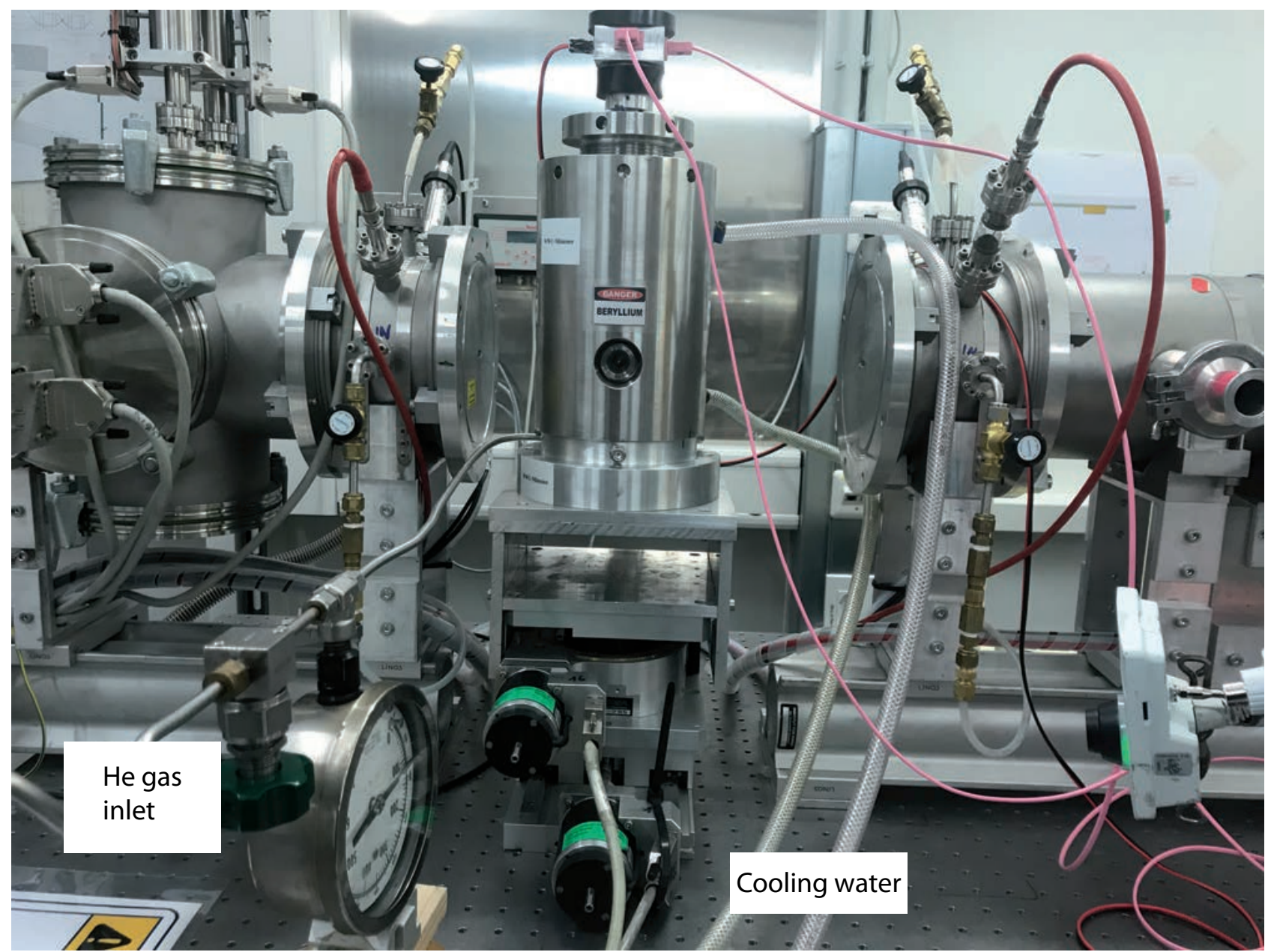

Fig. 4 Photograph of the autoclave installed at beamline P65 at DESY, the beam enters from the left hand side. The autoclave is mounted between the two the ionization chambers which are used to measure the Xray intensities before and after the sample.

\section{Possible applications of the autoclave and first test measurements}

The new autoclave at DESY may be used for studies of mineral solubilities in hydrothermal fluids, and for the speciation analysis of metals and other elements in fluids at high pressures and high temperatures. It is especially suited to study mineral solubilities and metal speciation in highly aggressive, chemically reactive fluids with significant amounts of $\mathrm{Cl}, \mathrm{S}$, and $\mathrm{F}$, all of which are important ligands in natural ore forming fluids in the Earth's crust ${ }^{26-29}$.

The pressures and temperatures that can be reached in the autoclave critically depend on the quality of the seals and the window materials. So far, we have run experiments at $\mathrm{P}<600$ bar and $\mathrm{T}<550^{\circ} \mathrm{C}$.

We conducted first test experiments at beamline P65 of Petra III at DESY in Hamburg in transition mode only. In this particular project we aimed to study the solubility of ore metals (e.g., W, Zr, $\mathrm{Hf}$, REE) in hydrothermal fluids and the speciation of these metals in fluids of near-natural compositions. Spectra were recorded in fluids with dissolving scheelite $\left(\mathrm{CaWO}_{4}\right)$. The element 
content in the fluid is determined using height of the edge-jump in X-ray absorption spectra (e.g. ${ }^{30}$ ). Fig. 5A shows the height of the edge-jump at W L3-edge for a single spectrum of each experiment. In the chosen representation, the edge jump is hardly visible in the run with scheelite in pure $\mathrm{H}_{2} \mathrm{O}$ and demonstrates that the measurements resulted in $\mathrm{W}$ concentrations of $7^{\star} 10^{-5} \mathrm{~mol}$ $\mathrm{W} / \mathrm{kg} \mathrm{H}{ }_{2} \mathrm{O}$, which is close to the detection limit that is estimated to be between 1 and $10 \mu \mathrm{g} / \mathrm{g}$ for $W$. The data show also that the concentration of $W$ in the fluid increases with increasing $\mathrm{HCl}$ concentration of the solution to a maximum value of $1.47^{\star} 10^{-2} \mathrm{~mol} \mathrm{~W} / \mathrm{kg} \mathrm{H} \mathrm{H}_{2} \mathrm{O}$. Tungsten concentrations calculated do only represent concentrations at a given time. Determination of tungsten solubility in these runs is not possible due to incongruent dissolution of scheelite in some of the experiments.

Fig. 5B shows normalized XANES spectra of the same experiments. Numbers given in brackets correspond to the number of single spectra that were collected and summed up. For comparison, normalized XANES spectra of $\mathrm{H}_{2} \mathrm{O}$ and a $0.05 \mathrm{~mol} / \mathrm{L} \mathrm{HCl}$ solutions containing $0.03 \mathrm{~mol} / \mathrm{L} \mathrm{Na}_{2} \mathrm{WO}_{4}$ are presented. In contrast to scheelite, $\mathrm{Na}_{2} \mathrm{WO}_{4}$ is highly soluble in aqueous fluids. Thus, high quality XAFS spectra are easily obtained.

The comparison between the two kinds of experiments demonstrates the quality of our measurements and highlights the fundamental difference of spectra measured in $\mathrm{HCl}$-solutions and $\mathrm{H}_{2} \mathrm{O}$ in the energy region between 10210 and $10250 \mathrm{eV}$, which is related to the fundamental difference of W-species. In case of very dilute samples, e.g., in runs on scheelite dissolution in $\mathrm{H}_{2} \mathrm{O}$, averaging of consecutive measured single spectra results in a reasonably acceptable XANES spectrum. However, for a better spectral quality in such cases and measurement of the EXAFS region measurements need to be taken in fluorescence mode.

EXAFS spectra measured in some of the samples are shown in Fig. 6A. A Spectrum taken of a $0.03 \mathrm{~mol} / \mathrm{L} \mathrm{Na} \mathrm{WO}_{4}$-solution in $\mathrm{H}_{2} \mathrm{O}$ at 100 bar at beamline $\mathrm{P} 65$ (DESY) is compared to one of an identical solution measured at the FAME beamline (ESRF) at 600 bar. For both experiments, Fourier transformed EXAFS spectra (Fig. 6B) show only a single contribution from the first oxygen coordination shell in a very similar manner. Both beamlines and setups allow measuring extended EXAFS spectra up to high k-values. The spectrum of $0.03 \mathrm{~mol} / \mathrm{L} \mathrm{Na} \mathrm{WO}_{4}$-solution in hydrochloric acid looks fundamentally different and indicates a more complex first oxygen coordination shell and contribution by W-W scattering paths in the second coordination shell. The spectrum taken on the scheelite dissolution in $\mathrm{HCl}$-solutions resembles the former one to a large extent, although the quality of the signal at $k>12$ is not sufficient for further analysis. The spectra reflect the wellknown fact that the $\mathrm{W}$-species in solution strongly depend on the $\mathrm{pH}$ of the solution (e.g. ${ }^{31,32}$ ). A thorough analysis is beyond the scope of this publication and will be provided elsewhere. 

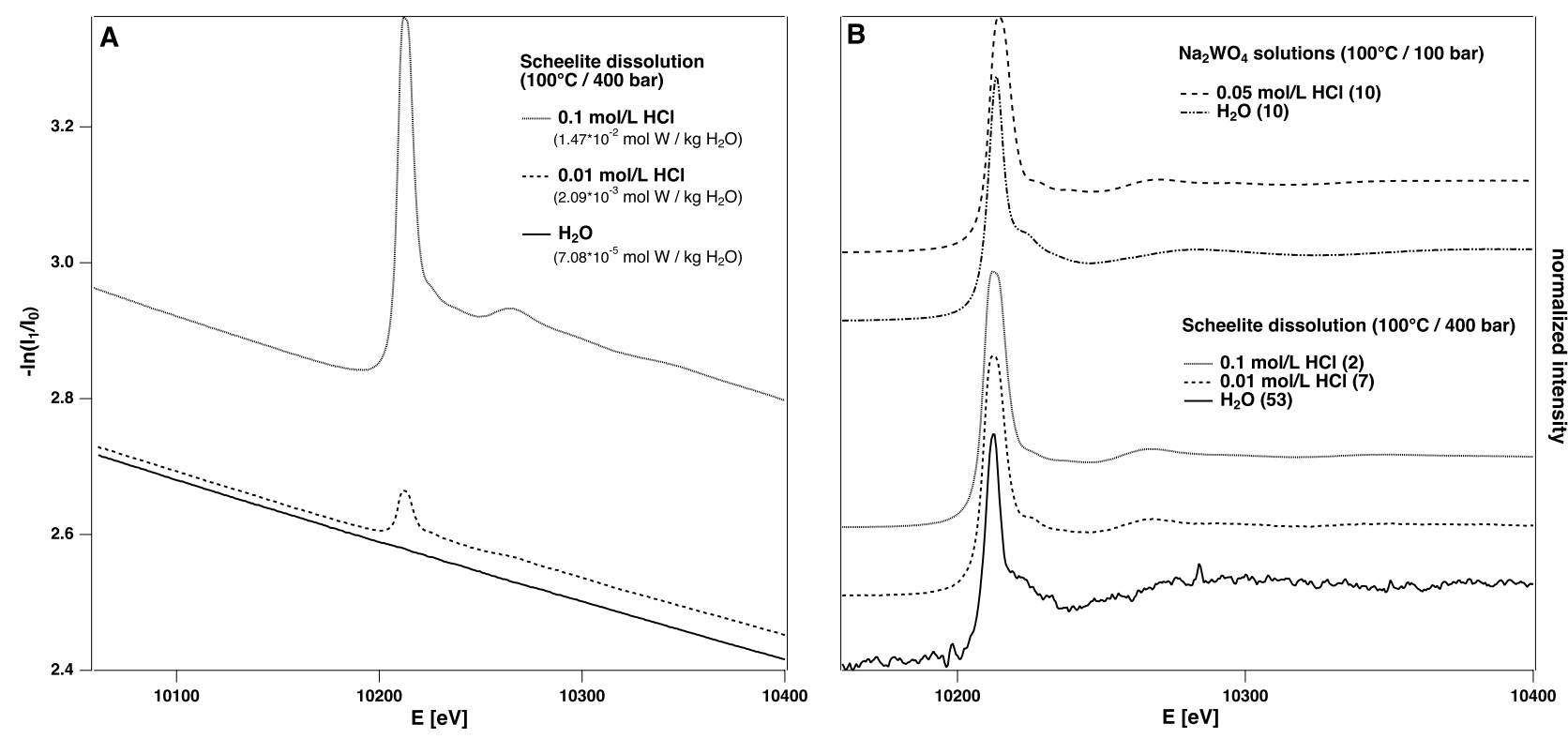

Fig. 5. A: Results from scheelite $\left(\mathrm{CaWO}_{4}\right)$ dissolution experiments in various fluid compositions at $100^{\circ} \mathrm{C}$ and 400 bar. $\mathrm{W} \mathrm{L}_{3}$-edge XAFS transmission spectra were collected at P65 at DESY using continuous scan mode. Counting time per single spectrum is $180 \mathrm{~s}$. The left figure shows single raw XAFS spectra. Tungsten aqueous concentration is calculated using the edge height jump of the X-ray absorption spectra as described in ${ }^{30}$. The diagram on the right (B) shows normalized XANES spectra of the same experiments. Numbers given in brackets correspond to the number of single spectra that were collected and summed up. In addition, normalized XAFS spectra on solutions containing $0.03 \mathrm{~mol} / \mathrm{L} \mathrm{Na}_{2} \mathrm{WO}_{4}$ in $\mathrm{H}_{2} \mathrm{O}$ or $0.05 \mathrm{~mol} / \mathrm{L} \mathrm{HCl}$ are presented.
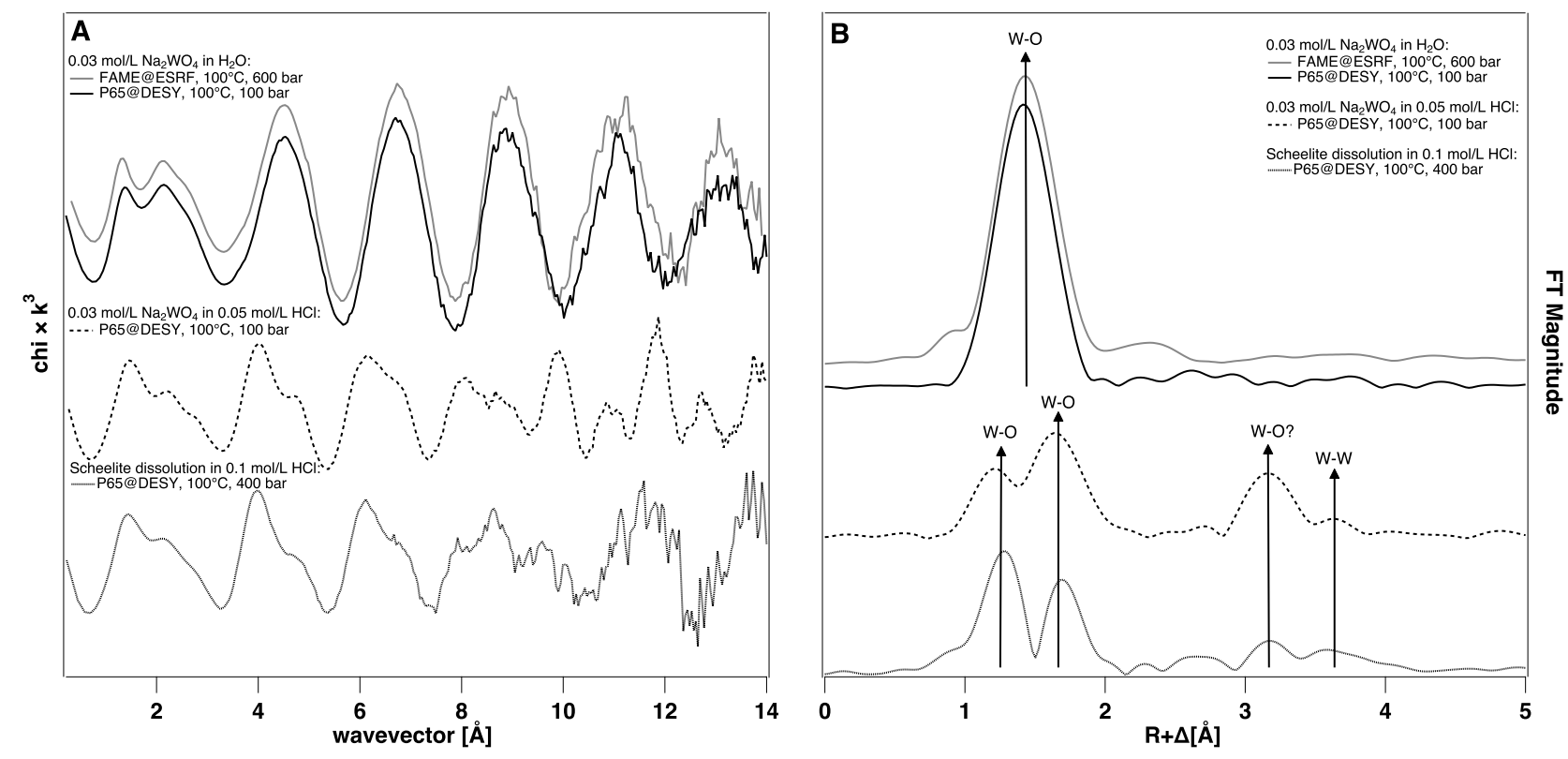

Fig 6: A: EXAFS $\chi(\mathrm{k}) \times \mathrm{k}^{3}$ oscillations extracted from transmission spectra of solutions containing 0.03 $\mathrm{mol} / \mathrm{L} \mathrm{Na} \mathrm{WO}_{4}$ in $\mathrm{H}_{2} \mathrm{O}$ or $0.05 \mathrm{~mol} / \mathrm{L} \mathrm{HCl}$ at $100^{\circ} \mathrm{C}$ and 100 or 600 bar and from a scheelite dissolution experiment in $0.1 \mathrm{~mol} / \mathrm{L} \mathrm{HCl}$ at $100^{\circ} \mathrm{C}$ and 400 bar. Two data sets on $\mathrm{Na}_{2} \mathrm{WO}_{4}$ in $\mathrm{H}_{2} \mathrm{O}$ are presented in order to compare results from P65 (DESY) and FAME (ESRF). Data collected at P65 were measured in continuous scan mode while at FAME a step-scan mode was used. This is also reflected in much longer acquisition time per spectrum at FAME (ca. 36 minutes per spectrum) compared to DESY. B: Fourier transforms of the W L3-edge EXAFS spectra for the same solutions. 
The results show clearly that the autoclave is well suited to study solubilities and dissolution kinetics of ore forming minerals in fluids of complex compositions. Furthermore, the autoclave can also be used to produce high-quality EXAFS spectra that allow investigating the speciation of these trace elements in fluids at high pressures and high temperatures.

\section{Funding}

Bundesministerium für Bildung und Forschung (BMBF) grant FKZ 05K16PMA, DESY Center for Molecular Water Science - Early Science Project. A. Loges was funded by the Deutsche Forschungsgemeinschaft (DFG, German Research Foundation) - Project-ID 387284271 - SFB 1349

\section{Author's contributions}

All authors contributed equally to the manuscript

\section{Data availability statement}

Data available on request from the authors

\section{Acknowledgements}

We acknowledge DESY (Hamburg, Germany), a member of the Helmholtz Association HGF, for the provision of experimental facilities and support within the new Center for Molecular Water Science (CMWS). Parts of this research were carried out at DESY beamline P65 and we would like to thank W. Caliebe (P64), M. Hermann and R. Nemausat, for their excellent support, and A. Ciabano for her generous help and sterling assistance in the chemical laboratories at DESY. Parts of this research were also carried out at FAME at ESRF, France and our sincere thanks go to the FAME staff for excellent support. Further thanks go to H.-P. Liermann for his general support of the project within the CMWS at DESY, and J. Berndt and B. Schmitte for their help with the EPMA and LA-ICPMS measurements at WWU Münster.

\section{References}

${ }^{1}$ C. A. Heinrich, D. Günther, A. Audetat, T. Ulrich and R. Frischknecht, Geology, 27, 755 (1999).

${ }^{2}$ E. Roedder, Econ Geol, 66, 98 (1971). 
3J. J. Wilkinson, Lithos, 55, 229 (2001).

${ }^{4}$ L. Scholten, C. Schmidt, P. Lecumberri-Sanchez, M. Newville, A. Lanzirotti, M.-L.-C. Sirbescu and M. Steele-Maclnnis, Geochim Cosmochim Acta, 252, 126 (2019).

${ }^{5}$ C. Schmidt, Geochim Cosmochim Acta, 220, 499 (2018).

${ }^{6}$ D. Testemale, J. Brugger, W. Liu, B. Etschmann and J. L. Hazemann, Chem Geol, 264, 295 (2009).

${ }^{7}$ W. A. Bassett, A. H. Shen, M. Bucknum and I. M. Chou, Rev Sci Instr, 64, 2340 (1993).

${ }^{8} \mathrm{C}$. Schmidt and I.-M. Chou, Raman spectroscopy applied to Earth sciences and cultural heritage, eds. J. Dubessy, M.-C. Caumon and R. Rull (Mineral Soc Gr Britain and Ireland, London, 2012). ${ }^{9}$ A. J. Anderson, H. Yan, R. A. Mayanovic, G. Solferino and C. J. Benmore, High Press Res, 34, 100 (2014).

${ }^{10}$ M. Borchert, M. Wilke, C. Schmidt, K. Kvashnina and S. Jahn, Geochim Cosmochim Acta, 142, 535 (2014).

${ }^{11}$ M. Borchert, M. Wilke, C. Schmidt, J. Cauzid and R. Tucoulou, Chem Geol, 276, 225 (2010).

${ }^{12}$ H. Yan, R. A. Mayanovic, A. J. Anderson and P. R. Meredith, Nucl Instr Meth Phys Res A, 649, 207 (2011).

${ }^{13}$ M. Louvel, C. Sanchez-Valle, W. J. Malfait, D. Testemale and J. L. Hazemann, Geochim Cosmochim Acta, 104, 281 (2013).

${ }^{14}$ A. Anderson and R. Mayanovic, High Press Res, 36, 458 (2016).

${ }^{15}$ M. Wilke, K. Appel, L. Vincze, C. Schmidt, M. Borchert and S. Pascarelli, J Synchr Rad, 17, 669675 (2010).

${ }^{16}$ M. Borchert, M. Wilke, C. Schmidt and K. Rickers, Chem Geol, 259, 39 (2009).

${ }^{17}$ K. Tamura, M. Inui and S. Hosokawa, Rev Sci Instr, 66, 1382 (1995).

${ }^{18}$ D. Testemale, R. Argoud, O. Geaymond and J. L. Hazemann, Rev Sci Instr, 76, (2005).

${ }^{19}$ E. Welter, R. Chernikov, M. Herrmann and R. Remausat, AIP Conf Proc, 2054, (2019). 
${ }^{20}$ H. P. Liermann, Z. Konôpková, W. Morgenroth, K. Glazyrin, J. Bednarčik, E. E. McBride, S. Petitgirard, J. T. Delitz, M. Wendt, Y. Bican, A. Ehnes, I. Schwark, A. Rothkirch, M. Tischer, J. Heuer, H. Schulte-Schrepping, T. Kracht and H. Franz, J Synchr Rad, 22, 908 (2015).

${ }^{21}$ Z. Jenai, H. P. Liermann, R. Husband, A. S. J. Méndez, R. Pennicard, H. Marquardt, E. F. O'Bannon, A. Pakhomova, K. Z., G. K., M. Wendt, S. Wenz, E. E. McBride, W. Morgenroth, B. Winkler, A. Rothkirch, M. Hanfland and W. Evans, Rev Sci Instr, 90, (2019).

${ }^{22}$ D. Testemale, A. Prat, E. Lahera and J. L. Hazemann, Rev Sci Instr, 87, 075115 (2016).

${ }^{23}$ W. Wagner and A. Pruss, J. Phys. Chem. Ref. Data, 31, 387 (2002).

${ }^{24}$ W. T. Elam, B. D. Ravel and J. R. Sieber, Rad Phys Chem, 63, 121 (2002).

${ }^{25}$ R. Bruyère, A. Prat, C. Goujon and J.-L. Hazemann, J. Phys Conf Ser, 121, 122003 (2008).

${ }^{26}$ Y. Mei, D. M. Sherman, W. H. Liu, B. Etschmann, D. Testemale and J. Brugger, Geochim Cosmochim Acta, 150, 265 (2015).

${ }^{27}$ L. Scholten, A. Watenphul, O. Beermann, D. Testemale, D. Ames and C. Schmidt, Geochim Cosmochim Acta, 224, 187 (2018).

${ }^{28}$ Y. L. Xing, B. Etschmann, W. H. Liu, Y. Mei, Y. Shvarov, D. Testemale, A. Tomkins and J. Brugger, Chem Geol, 504, 158 (2019).

${ }^{29}$ M. Louvel, A. Bordage, B. Tripoli, D. Testemale, J. L. Hazemann and J. Mavrogenes, Chem Geol, 466, 500 (2017).

${ }^{30}$ G. S. Pokrovski, J. Roux, J. L. Hazemann and D. Testemale, Chem Geol, 217, 127 (2005).

${ }^{31}$ M. M. Hoffmann, J. G. Darab, S. M. Heald, C. R. Yonker and J. L. Fulton, Chem Geol, 167, 89 (2000).

${ }^{32}$ S. A. Wood and D. Vlassopoulos, Geochim Cosmochim Acta, 53, 303 (1989). 